\title{
Francisco del Pinal: Atlas of distal radius fractures (With e-book)
}

\section{Thieme Verlag, New York, Stuttgart, Delhi, Rio de Janeiro, 2018, 392 pp. 684 figs., Hardcover, EUR(D) 204,99 EUR(A) 210,80 CHF 236,00, ISBN: 978-1-62623-679-0}

\author{
Alain G. Graftiaux ${ }^{1} \cdot$ Pierre H. Kehr ${ }^{1}$
}

Received: 27 February 2019 / Accepted: 20 July 2019 / Published online: 25 July 2019

(c) Springer-Verlag France SAS, part of Springer Nature 2019

This book contains the considerable and recognized experience of its author in arthroscopic techniques and fractures. The rich illustrations make it a particularly useful book, easy to access and very practical for surgical implementation.

This book is divided into different parts. The first chapter gives general information on the management of radial fractures and arthroscopy. The following chapters deal with the peculiarities of the management of different types of fractures, including unclassifiable explosion fractures. The book ends on the vicious callus related to insufficient initial care but for which treatment can be attempted.

The numerous arthroscopic drawings and views as well as a step-by-step description will be useful to all surgeons in charge of fractures of the radius.
On the other hand, Internet access is provided to complete the book.

\section{Compliance with ethical standards}

Conflict of interest The authors declare that they have no competing interests.

Publisher's Note Springer Nature remains neutral with regard to jurisdictional claims in published maps and institutional affiliations.
Pierre H. Kehr

pierre.kehr@gmail.com

1 Strasbourg, France 